\title{
Adolescent Risk: The Co-Occurrence of Illness, Suicidality, and Substance Use
}

\author{
Gebhard Hüsler, ${ }^{1}$ Ronny Blakeney, ${ }^{2}$ and Egon Werlen ${ }^{3}$
}

Received August 7, 2003; revised March 15, 2005; accepted May 25, 2005

\begin{abstract}
Illness is rarely considered a "risk factor" in adolescence. This study tests illness, suicidality and substance use as outcome measures in a path analysis of 1028 Swiss adolescents in secondary prevention programs. The model showed that negative mood (depression and anxiety) predicted two paths. One path led from negative mood to suicidality and from there to substance use. The other path led directly from negative mood to illness. Traditional protective factors (good relationships, secure identity) protected against the negative mood-suicide-substance path, but not against the negative mood-illness path.
\end{abstract}

KEY WORDS: adolescent at risk; illness; suicidality; substance use.

\section{ILLNESS, SUICIDALITY, AND SUBSTANCE USE}

Research on risk and protection (RAP) in adolescence identifies an array of macro, micro, intra- and interpersonal factors which, in various combinations and interactions contribute to young people either being vulnerable to or resisting all manner of potential risks. In a recent study Narring et al. (2003) found that among 9268 Swiss adolescents, those who identified themselves as having chronic conditions (such as diabetes, asthma, or heart disease) were more likely than adolescents without health problems to engage in dangerous behavior including driving without seat belts, drink driving, substance use and suicide attempts. Poor health is associated with poverty, acting out, negative mood, suicidality, and difficult family

\footnotetext{
${ }^{1}$ Gebhard Hüsler, psychologist and psychotherapist, Director of the Centre for Rehabilitation and Health Psychology Research, University of Fribourg, rte Englisberg 7, CH 1763 Granges-Paccot, Switzerland. To whom correspondence should be addressed; e-mail: gebhard. huesler@unifr.ch.

${ }^{2}$ Ronny Blakeney is a senior researcher at University of Fribourg, Departement Erziehungswissenschaften, University of Fribourg, rue de Faucigny 2, CH-1700 Fribourg, Switzerland. Her major research interests are developmental approaches to the sociomoral challenges of adolescents.

${ }^{3}$ Egon Werlen is a junior researcher at Center of Rehabilitation and Health Psychology Research, rte Englisberg 7, CH 1763 GrangesPaccot, Switzerland. His major interests are the course of psychological well being, psychological processes in chronic diseases, and methodological issues.
}

relationships, all of which are associated with vulnerability. Nevertheless, research on adolescent RAP factors that address health typically defines "health risks" behaviorally, for example, as personal safety, violence, substance use, suicide attempts, premature sexuality and so on. In other words, health status-which is measured in other age groups by physical symptoms of illness, or doctor visits-is rarely seen as either an outcome or an RAP factor in adolescence.

RAP factors have been successfully modeled using path models to predict outcomes based on interactions. The aim of this paper is to propose and test a Structural Interactive Path (SIP) model of adolescent risk and protective factors that includes illness as well as suicidality and use of tobacco, alcohol, and cannabis as interacting outcome measures. One caveat about the choice of outcome measures: Generally, one study's outcome measure is another study's risk factor. For example, substance use, negative mood and suicide have each been seen as a risk for one of the others. In this paper we examine the interaction of the outcome measures as risk factors for each other, as well as outcome measures for other risks.

\section{NEGATIVE MOOD AS A RISK FACTOR}

\section{Negative Mood and Illness}

Recent studies document the predictive association between negative mood and illness in nonelderly patients 
(Berardi et al., 2002; Ormel et al., 1999). Berardi et al. (2002) found that among 1896 primary care patients in Italy aged 14 and over, 7.8-9\% presented as depressed, and depression was related to severity of physical illness as well as to disability. The Berardi findings fail to address the question of the order of onset: Which came first, illness or depression? Ormel et al. (1999) specifically address the role of depression as a predictor of illness in a study of 1051 nonelderly people in The Netherlands who consulted a medical doctor. They found that $14 \%$ were depressed but disability free at time of first consultation. Patients assessed as depressed but disability free at first visit were 1.5 times more likely to develop a physical illness/disability at 3-month follow-up and 1.8 times more likely to have a physical disability at 12-month follow-up. This suggests that depression and/or negative mood precedes the onset of physical symptoms. However, Hotopf et al. (1998) in a longitudinal cohort study in the United Kingdom found that abdominal pain in adolescence was associated with psychiatric disorder in adulthood. Concerning emotionality and physical symptoms, Egger et al. (1999) showed a strong relationship between emotional disorder and somatic complaints in younger adolescents (9-16 years). There were gender, illness and complaint specific associations in boys and girls. Williams et al. (2002) examined the concurrent and longitudinal relations between selfassessed health, and depressive symptoms among adolescents. Physical symptom reports were related to depressive symptoms both concurrently and longitudinally.

In addition, research indicates that depression onset is occurring earlier in life today than in past decades. A recently published longitudinal prospective study found that early-onset depression often persists, recurs, and continues into adulthood, and indicates that depression in youth may also predict more severe illness in adult life. Depression in young people often co-occurs with other mental disorders, most commonly anxiety, disruptive behavior, or substance abuse disorders, and with physical illnesses, such as diabetes (Boice, 1998).

Thus there are consistent reports of the association between negative mood variables and physical illness, yet the logical and chronological relationships demand further exploration, particularly among adolescents, since both illness and negative mood in adolescence are predictive of problematic life course.

\section{Negative Mood and Suicidality}

Both negative mood and substance use have been associated with risk for suicide in adolescence (Giaconia et al., 2001). In 1997, suicide was the 3rd leading cause of death among 10-24-year-olds in the United States. NIMH-supported researchers (National Institute of Mental Health, 2003) found that among adolescents who develop major depressive disorder, as many as $7 \%$ may commit suicide in the young adult years. Predictably, depression in children and adolescents is associated with an increased risk of suicidal behaviors. This risk may rise, particularly among adolescent boys, if the depression is accompanied by conduct disorder and alcohol or other substance abuse. Finally, in an extensive review of the literature on the relationship between adolescent suicidality and risk factors, Beautrais (2000) found that the risk of suicidal behavior increases among young people who have a mood disorder or are involved in harmful use of drugs including alcohol.

\section{Negative Mood and Substance Use}

The National Institute of Mental Health (2002) estimates that at least $2.5 \%$ of children under the age of 18 (1.8 million American children) are "severely depressed." The American Academy of Child and Adolescent Psychiatry (Giaconia et al., 2001) places the number at 5\% (3.4 million). A number of epidemiological studies have reported that up to $2.5 \%$ of children and up to $8.3 \%$ of adolescents in the United States suffer from depression. Negative mood includes both anxiety and depression. Anxiety has been seen as predisposing teenage boys to drug use, and depression has been examined as both prior to and subsequent to both drug use and suicide attempts (Berardi et al., 2002; Christie et al., 1988). A number of studies on general populations have shown comorbidity between depressive mood and substance use (Brown et al., 1996; Fergusson et al., 1996; Michel et al., 1998; Brook et al., 1998). According to Henry et al. (1993), depressive mood precedes substance use at the age of 15 , but only in boys. A recently presented review showed that psychosocial problems might be more a cause than a consequence of cannabis use, especially with regard to associations between use and mental illness (MacLeod et al., 2004). Wilens et al. (1997) also confirm that anxiety precedes substance use in adolescents. However, an epidemiological study on a very large number of adolescents has shown that substance use precedes depressive mood (Burke et al., 1994). Contrary to these findings, Deykin et al. (1987) found that both drug use and alcohol use were followed by anxious disturbances. Christie et al. (1988) reported that being anxious doubled the risk of using drugs. Trait anxiety and anxiety sensitivity were found to be important personality risk factors for substance use (tobacco, alcohol and cannabis; Comeau 
et al., 2001). Norton (2001) reports the same results. In short, depressive mood, anxiety and conduct disorders are the most often mentioned intra-personal predictors of substance use. However, these mental disorders have also been observed as consequences of substance use.

\section{SECURE SELF AS A PROTECTIVE FACTOR}

A secure self, based on self-esteem and self-worth, is an emotional component of self-evaluation of personal qualities and competencies. The term self-esteem and selfworth are most commonly used to describe a global view of self, without reference to specific competencies (Harter and Marold, 1994; Rosenberg et al., 1995). Studies of self-esteem in adolescence have consistently found more positive self-esteem in males than in females (Statham and Roades, 2001). Some studies have also reported age trends, with levels of self-esteem increasing across adolescence (Block and Robins, 1993). Rosenberg reported in 2 papers on a longitudinal study of boys who were in the 10th grade (Rosenberg et al., 1989; Rosenberg et al., 1995). Data from 1886 boys who participated in the first 2 waves of data collection were included. In the 1 st of these studies, Rosenberg et al. (1989) assessed reciprocal relations between global self-esteem and depressive affect. They significantly affected each other, but the negative relationship between these 2 measures was due more to the effects of depressive mood on self-esteem than the reverse. In contrast, relations between grades and selfesteem were primarily attributable to effects of school performance on self-esteem, rather than the reverse. "The significant effect of school marks on self-esteem lends support to self-esteem theory. If superior performance within a valued arena of achievement - academic performance - produces favorable reflected appraisals, social comparisons, and self attributions, then we can understand why grades exercise a positive effect on global self-esteem" (Rosenberg et al., 1989, p. 1012).

In the 2nd study (Rosenberg et al., 1995) these researchers further examined associations between both specific and global self-esteem and affective and behavioral outcome measures. They found substantially higher correlations between measures of positive affect (happiness, life satisfaction) or negative affect (depression, general anxiety, irritability, negative affective states) and global self-esteem than between the same measures and academic self-esteem.

Block et al. (1991) examined the consistency of negative affect from childhood through late adolescence. They found that depressive symptoms at age 18 were associated with personality characteristics at earlier ages. Further they found that, by age 7 , boys who were later identified as being depressed tended to be described by their teachers as aggressive, undercontrolled, and limit testing. Girls reporting relatively high levels of depression, on the other hand, tended to be seen as academically bright and thoughtful. Depression at age 18 was associated with low self-esteem for girls, but not for boys.

\section{Secure Self and Illness}

While there is little literature that directly assesses the relationship between self-esteem and physical health, there are a myriad of reports (MacLeod and Austin, 2003) on the self-esteem or stigma concerns of adolescents with chronic health conditions (e.g. epilepsy). Our concern with illness as an adolescent risk factor alerts us to the co-occurrence of lowered self-esteem and physical illness in adolescent suicidality (Guillon et al., 2003). In general, depression and self-esteem are seen as the inverse of one another (Shrier et al., 2001), and the relationship between depression and illness (that is, the inverse of secure self) is well documented.

\section{Secure Self and Suicidality}

Recent research has noted the correlation between self-esteem and psychological resilience even among at risk youth. Csorba et al. (2003) for example, in a study of 490 consecutively referred 8-17-year-old outpatients, found that suicidal youth differed from nonsuicidal depressed youth on only 3 of 130 items: negative selfesteem, hopelessness, and proneness to violence. Put another way, positive self-esteem could be considered a protective factor against suicide attempts and suicidal ideation. Guillon et al. (2003) also found that suicidal adolescents had significantly lower self-esteem than adolescents with other clinical diagnoses. Thus we expect a secure sense of self to be protective against suicidality.

\section{Secure Self and Substance Use}

One body of literature that looks at resilient coping examines the relationship of school adjustment, behavioral self-regulation, self-confidence, competence, selfefficacy and self-control to protection from the temptations of delinquent peers and substance use (Byrne, 2000; Hawkins et al., 1992). These variables can be said to represent a developmental re-organization of a secure sense of self in relation to the environment (Levitt and Selman, 
1996). A number of studies pursuing the same line of questioning (e.g. McGee and Williams, 2000) have shown negative relationships among measures of self-concept and substance use.

\section{FAMILY RELATIONS AS A PROTECTIVE FACTOR}

Good family relations are consistently associated with protection against early onset and prolonged substance use in adolescence, while negative family relations create vulnerability for both suicidality and substance use.

\section{Family Relations and IIlness}

A number of previous studies have suggested that children from single-parent families are likely to be in poorer health compared with other children (Wadsworth et al., 1983; Mauldon, 1990; Montgomery et al., 1996). The risk of accidental injuries and infections, in particular, seems to be elevated among children from single-parent families (Moyes, 1980; Wadsworth et al., 1983; Roberts, 1994; Fleming and Charlton, 1998). The risk increase seems to vary from 2- to over 3-fold (Roberts, 1994; Fleming and Charlton, 1998). Low income, poor housing, and lack of supervision together with stress and insecurity of a single-parent in child rearing have been suggested to explain the increased risk of illness and accidental injury among children in single-parent households (Wadsworth et al., 1983; Fleming and Charlton, 1998). All of these factors, in turn, (low income, bad neighborhood, parental stress) have been identified as RAP factors. Adolescents from single-parent families also had more somatic complaints (aches and pains, palpitations, nausea, dizziness, difficulties falling asleep, irregular bowel function, and heartburn) than other adolescents (Aro, 1989; Aro and Palosaari, 1992), but according to some studies the difference was apparent only for females (De Goede and Spruijt, 1996). On the other hand, Wingert et al. (1968) and Brink and Vanderpool (1982) found no relationship between family background and physical illness or hospitalization. Parallel findings of an increased risk of physical illness among the adult offspring of single-parent families emerged in a recent case-control study by Agid et al. (1999). Subjects with early parental loss (due to parental death or permanent separation) reported statistically significantly more cases of physical illness than other subjects (45.8\% vs. $15.1 \%$, $p=0.01)$.

\section{Family Relations and Suicidality}

Good family relationships are said to protect against adolescent suicide. Zweig et al. (2002), in a study of over 12,000 American adolescents, found that good family relations were associated with lower risks for suicidality as well as lower risks for substance use.

\section{Family Relations and Substance Use}

Previous research (Wills et al., 2001) had shown that parental support is inversely related to substance use. In a sample of 3984 young adolescents in 5 European cities McArdie et al. (2002) found that confiding in mother was the most significant protective factor against drug use. In 4 out of 5 cities, living with both parents was a protective barrier against drug use. Parental supervision offered protection, regardless of family constellation. Only in Dublin did peers have a greater influence than parents.

\section{A THEORETICAL MODEL}

In this paper we propose and test a SIP model with illness, suicide and substance use. Negative mood has been associated with all three outcomes. What paths lead from negative mood to each of the outcomes? What are the relationships among illness, suicidality and substance use for at risk adolescents? Poor family relations have been associated with all 3 outcomes, and variables associated with a secure sense of self have been seen as protective of both suicide and substance use. We therefore proposed to test the following SIP model (Fig. 1).

To summarize we can formulate the following model:

1. Negative mood (depression, anxiety)

(a) represents a risk factor for higher suicidal thinking which in turn is a risk for substance use,

(b) is a leading indicator for other illness related concerns, and (c) is negatively associated with the relationship with parents.

2. Secure self (self-esteem, self-efficacy) is regarded as a direct protective factor against suicidal thinking and indirectly protects against substance use.

3. Secure self is connected to a good relationship with parents and protects against substance use.

4. A good relationship with parents is also a protective factor against suicidal thinking.

5. Protective factors have little or no effects on illness but risk factors do. 


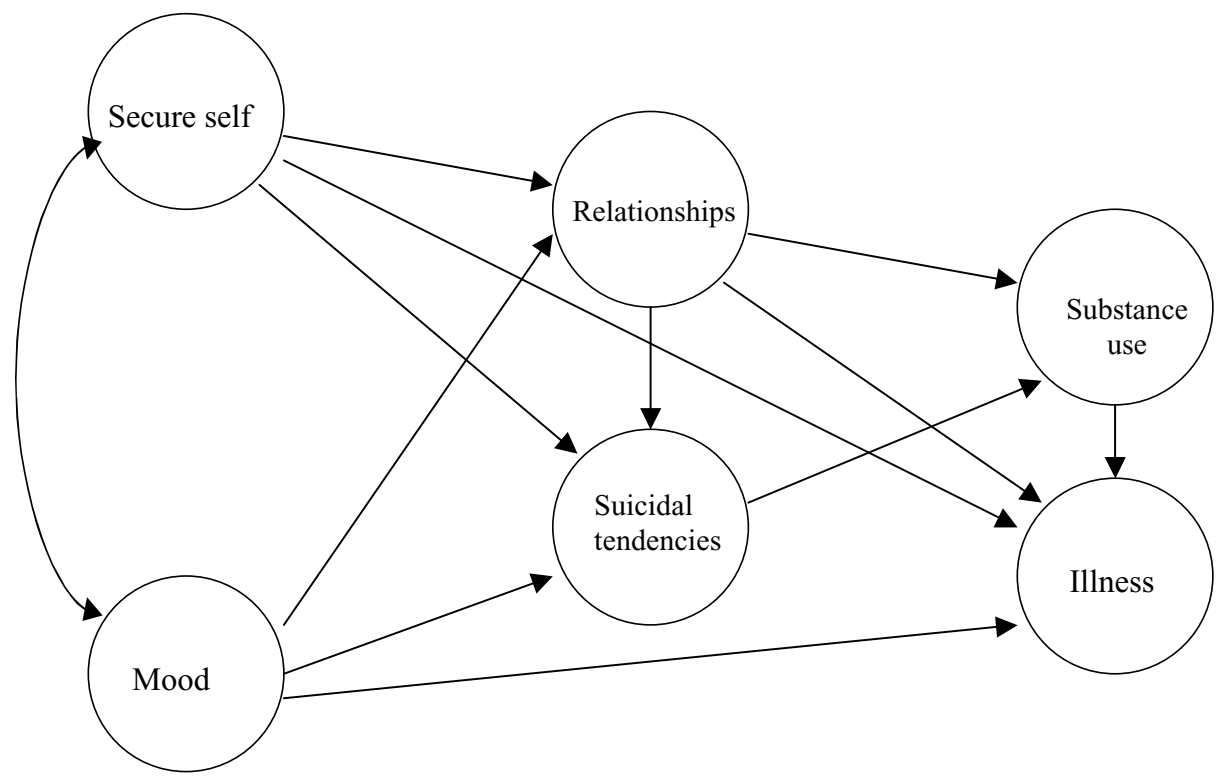

Fig. 1. Theoretical model.

6. In general for all hypotheses effects should vary by age and gender.

To test these hypotheses we use a path model.

\section{METHODS}

supra-f (Sucht-Prävention Forschung) is a national project begun in 1999 with the aim of answering the following question: What works in secondary prevention for adolescents at risk? The national projects, initiated by the Swiss Federal Office of Public Health, were implemented by 12 intervention centers across Switzerland. These centers vary in their concepts, depending on the local sites' perception of need, the local resources available, and each community's approach to intervention.

The supra- $f$ programs target adolescents aged 1120 who face situations that place them at risk of school dropout, substance use or deviant behavior. The sample consists of 1028 adolescents. There are twice as many boys than girls. The younger boys and girls (11-15) are in school, the older ones (16-20) have a professional background. Criteria for inclusion in the program are one or more of the following: (a) substance use, (b) deviant behavior, (c) school absenteeism or dropping out of vocational training, (d) family problems, and/or (e) psychological problems.

\section{PROCEDURE}

Data were collected at entry to the program with a self-report questionnaire and an interview. The questionnaire took about $45 \mathrm{~min}$ to administer, the interview about $18 \mathrm{~min}$. The staff could be asked for help in case of need (e.g., not understanding the sense of a question). The survey was administered under conditions of confidentiality. The adolescent's results were coded to protect confidentiality of data.

\section{MEASURES}

The questionnaires can be classified as including (1) sociodemographical data, (2) psychological data, (3) drug use, (4) physical complaints, and (5) contacts with the health system. Items on sociodemographic characteristics included age, gender, family and school background. The psychological data included depression, a 15 item questionnaire with a 5-point Likert scale (item example: "I was sad," scale: rarely or not at all-less than 1 day weekly to mostly-5 to 7 days weekly; Hautzinger and Bailer, 1993), two instruments for anxiety: the German version of the SCL-90-R Anxiety Scale (example: "Within the last week I have been anxious"; Franke, 1995) and the trait version of the STAI by Laux et al. (1981), measures of self-image (example: "I am sure that I do the right things"; Harter, 1982), self-efficacy (example: "Whatever happens I will cope with it," Jerusalem and Schwarzer, 
Table I. Scales and Reliability of the Instruments Used

\begin{tabular}{|c|c|c|c|c|}
\hline & Items & & Alpha & Authors \\
\hline Depression & 15 & 5-Point scale & 0.89 & Hautzinger and Bailer (1993) \\
\hline Anxiety (SCL-90-R) & 10 & 4-Point scale & 0.89 & Franke (1995) \\
\hline Anxiety (STAI trait) & 20 & 4-Point scale & 0.90 & Laux et al. (1981) \\
\hline Self-esteem & 7 & 4-Point scale & 0.84 & Harter (1982) \\
\hline Self-efficacy & 10 & 4-Point scale & 0.83 & Jerusalem and Schwarzer (1999) \\
\hline Relationship with parents: cohesion & 3 & 4-Point scale & 0.59 & Armsden and Greenberg (1987) \\
\hline Relationship with parents: emotional & 5 & 4-Point scale & 0.85 & Armsden and Greenberg (1987) \\
\hline Suicidal thinking; attempts & 3 & 2-Point scale & 0.62 & $\begin{array}{l}\text { Arènes et al. (1998); Ferron et al. (1997); } \\
\quad \text { Narring et al. (1994) }\end{array}$ \\
\hline List of physical complaints & 14 & 4-Point scale & 0.82 & Ferron et al. 1997; Narring et al. 1994 \\
\hline Alcohol use & 5 & 6-Point scale & 0.84 & Arènes et al. (1998); Narring et al. (1994) \\
\hline Cannabis use & 1 & 5-Point scale & - & Arènes et al. (1998); Narring et al. (1994) \\
\hline Smoking & 1 & 6-Point scale & - & Arènes et al. (1998); Narring et al. (1994) \\
\hline List of contact to the health system & 11 & 4-Point scale & 0.60 & Ferron et al. (1997); Narring et al. (1994) \\
\hline
\end{tabular}

1992), relationship with parents (example: "My parents accept me as I am"; Armsden and Greenberg, 1987), and suicidal thinking and suicide attempts (example: "Have you thought about committing suicide within the last 12 months?"; Arènes et al., 1998; Ferron et al., 1997). We measured substance use including cigarette smoking (never to more than 20 daily), alcohol (never to every day) and cannabis use (never to every day) for the last 30 days (Arènes et al., 1998; Narring et al., 1994). The list of physical complaints and the list of contacts with health systems are reported in Ferron et al. (1997) and Narring et al. (1994). Validity data are reported in the respective works cited. In Table I we report the reliability for each measure.

\section{MODEL EVALUATION}

The study uses a structural equation model (SEM) as the main method of analysis. SEM is a multivariate statistical model that evaluates both the measurement quality of a set of variables used to measure a latent construct (the measurement model) and the relationship among the latent constructs (the structural model). A latent construct is a variable that is not directly measured. For example "mood" is the variable for depression and anxiety. We used Amos 4, a software package, to estimate structural relationships (Arbuckle and Wothke, 1999) for calculating the model.

\section{RESULTS}

There are boys (age $11-15, N=319$; age 16-20, $N=388$ ), and girls (age $11-15, N=124$; age 16-20, $N=197)$ living with both parents $(N=611)$, living with
1 parent $(N=230)$, living with nonparents $(N=52)$, and living alone $(N=27)$. There are some missing data for sociodemographic variables $(N=108)$.

Concerning the variables in the model (see Table II) results are as follows:

Mood: The latent variable created by depression and anxiety. Younger adolescents score lower while females of both age groups score higher than boys. All groups differ $(p \leq 0.05)$.

Secure self: The latent variable made up of selfefficacy and self-esteem differs between males and females $(p \leq 0.05)$.

Relationships: The latent variable made up of emotional relationships and cohesion with parents. On emotional relationship with parents all groups differ $(p \leq$ $0.05)$. On cohesion, females differ from males $(p \leq$ $0.05)$.

Suicidal tendencies: The latent variable made up of two items: thoughts about suicide and suicide attempts. In both variables girls have significantly higher values than boys ( $p \leq 0.05$ ), and older girls score higher on suicidal thinking than younger girls $(p \leq 0.05)$.

Substance use: The latent variable created from alcohol, tobacco and cannabis use. The younger adolescents score lower than older ones $(p \leq 0.05)$.

Illness: The latent variable created from health complaints and contacts with the health system (physicians, others). There is a difference on health complaints between boys and girls $(p \leq 0.05)$ and the older girls score higher than the younger ones $(p \leq 0.05)$. On health complaints and contact with the health system the older girls score highest, significantly different from all other groups ( $p \leq 0.05$ ), and the younger boys report less contact with the health systems than the girls of the same age $(p \leq 0.05)$. 
Table II. Means and Standard Deviations of Observed Variables in the Model by Age Groups and Gender

\begin{tabular}{|c|c|c|c|c|}
\hline & \multicolumn{2}{|c|}{ Age 11-15 (Mean (SD)) } & \multicolumn{2}{|c|}{ Age 16-20 (Mean (SD)) } \\
\hline & Male $(N=319)$ & Female $(N=124)$ & Male $(N=388)$ & Female $(N=197)$ \\
\hline \multicolumn{5}{|l|}{ Mood } \\
\hline Depression (0-45) & $9.00(7.54)$ & $14.63(10.26)$ & $10.36(8.05)$ & $16.69(9.74)$ \\
\hline Anxiety $(10-50)$ & $15.70(7.00)$ & $19.06(7.99)$ & $15.62(6.17)$ & $19.80(7.96)$ \\
\hline \multicolumn{5}{|l|}{ Secure } \\
\hline Self-efficacy (1-4) & $3.09(0.44)$ & $2.96(0.47)$ & $3.10(0.45)$ & $2.95(0.48)$ \\
\hline Self-esteem (1-4) & $3.26(0.51)$ & $3.08(0.65)$ & $3.32(0.51)$ & $3.00(0.65)$ \\
\hline \multicolumn{5}{|l|}{ Relationships } \\
\hline Emotional (1-4) & $3.34(0.66)$ & $3.00(0.74)$ & $3.19(0.67)$ & $2.86(0.78)$ \\
\hline Cohesion (1-4) & $3.30(0.65)$ & $3.13(0.69)$ & $3.23(0.65)$ & $3.09(0.69)$ \\
\hline \multicolumn{5}{|l|}{ Suicidal tendencies } \\
\hline Thinking (no/yes) & $0.21(0.41)$ & $0.45(0.50)$ & $0.27(0.44)$ & $0.62(0.49)$ \\
\hline Attempts (no/yes) & $0.14(0.45)$ & $0.46(0.70)$ & $0.16(0.46)$ & $0.48(0.68)$ \\
\hline \multicolumn{5}{|l|}{ Substance use } \\
\hline Alcohol (1-6) & $1.79(1.01)$ & $1.78(0.92)$ & $2.19(1.05)$ & $2.07(0.94)$ \\
\hline Tobacco $(1-6)$ & 2.44 (1.74) & $2.78(1.73)$ & $3.35(1.81)$ & $3.69(1.79)$ \\
\hline Cannabis (1-5) & $1.82(1.37)$ & $1.64(1.07)$ & $2.50(1.65)$ & $2.24(1.53)$ \\
\hline \multicolumn{5}{|l|}{ Illness } \\
\hline Complaints (1-4) & $1.42(0.32)$ & $1.77(0.46)$ & $1.49(0.39)$ & $1.94(0.50)$ \\
\hline \multicolumn{5}{|c|}{ Contact with medical services } \\
\hline Physicians (0-6) & $1.51(1.20)$ & $1.88(1.25)$ & $1.60(1.24)$ & $2.31(1.40)$ \\
\hline Therapists $(0-5)$ & $0.50(0.73)$ & $0.40(0.67)$ & $0.59(0.78)$ & $0.85(0.95)$ \\
\hline
\end{tabular}

Note. Alcohol: alcohol consumption the last 30 days, tobacco: do you smoke, cannabis: cannabis consumption the last 30 days.

These intercorrelations are comparable to those found by Metha et al. (1998). Table III presents the factor loadings and residuals of each of the indicator variables for their respective latent constructs. Most factors were significant $(p \leq 0.05)$ and most factor loadings are $>0.50$. This indicates that the indicator variables are a good measure of the latent constructs.

The model is presented with different age and gender groups as younger adolescents (11-15) differ in their development from older adolescents (16-20) and boys and girls differ in terms of RAP factors (Fig. 2, Table V).

\section{Risk Factors for Illness Suicidality, and Substance Use}

Intercorrelations among the risk factors (Table IV) show that the highest correlations are between negative mood and health (0.47), negative mood and suicidal ideation and behavior ( 0.40$)$, and between health and suicidality (0.35). As Fig. 2 shows, negative mood directly influenced both suicidal thinking and illness for all 4 age by gender groups. The risk of negative mood for suicide ranged from 0.39 to 0.52 , while the risk of negative mood for illness ranged from 0.37 to 0.53 . Within the SIP model, suicidal thinking functioned as a mediating factor for substance use ( 0.27 to 0.63$)$ except among the older girls $(0.04$ ns). Substance use acted as a low-level mediating factor for illness ( 0.19 to 0.24$)$, except among older boys ( 0.24 , ns). Secure self and negative mood are negatively related ( -.39 to -.58$)$. For all ages and both genders secure self is related to a good emotional and cohesive relationship with parents (0.39 to 0.60$)$. A good relationship with parents protects against substance use overall, but more for girls than for boys $(-0.25$ to -0.43 ; older boys $=-0.11$ ns). Secure self may be marginally risk against suicidal thinking for the younger boys (0.19), while for girls good relationships with their families are marginally protective against suicide $(-0.14$ to -0.31$)$.

\section{Results for the Different Subgroups}

Negative mood was a powerful direct predictor of both illness and suicidality. While age differences were apparent, gender differences were most striking. For boys, it was negative mood which led most frequently to suicidality and thence to substance use (younger boys 0.52 and 0.32 ; older boys 0.61 and 0.63 ). For girls, negative mood 
Table III. Standardized Factor Loadings by age and gender

\begin{tabular}{|c|c|c|c|c|}
\hline \multirow[b]{3}{*}{ Age } & \multicolumn{4}{|c|}{ Factor loadings } \\
\hline & \multicolumn{2}{|c|}{$11-15$} & \multicolumn{2}{|c|}{$16-20$} \\
\hline & Male & Female & Male & Female \\
\hline \multicolumn{5}{|l|}{ Mood } \\
\hline Depression & 0.84 & 0.84 & 0.88 & 0.79 \\
\hline Anxiety & 0.84 & 0.77 & 0.76 & 0.83 \\
\hline \multicolumn{5}{|l|}{ Secure self } \\
\hline Self-efficacy & 0.52 & 0.73 & 0.68 & 0.67 \\
\hline Self-esteem & 0.82 & 0.79 & 0.74 & 0.85 \\
\hline \multicolumn{5}{|l|}{ Relationships } \\
\hline Emotional & 0.84 & 0.87 & 0.79 & 0.94 \\
\hline Cohesion & 0.70 & 0.63 & 0.67 & 0.67 \\
\hline \multicolumn{5}{|l|}{ Suicidal tendencies } \\
\hline Suicidal thinking & 0.88 & 0.88 & 0.98 & 0.79 \\
\hline Suicidal attempts & 0.42 & 0.57 & 0.47 & 0.49 \\
\hline \multicolumn{5}{|l|}{ Substance use } \\
\hline Alcohol & 0.65 & 0.70 & 0.62 & 0.39 \\
\hline Tobacco & 0.61 & 0.63 & 0.49 & 0.58 \\
\hline Cannabis & 0.78 & 0.63 & 0.71 & 0.64 \\
\hline \multicolumn{5}{|l|}{ Illness } \\
\hline Complaints & 0.76 & 0.84 & 0.86 & 0.72 \\
\hline $\begin{array}{r}\text { Contact with } \\
\text { physicians }\end{array}$ & 0.37 & 0.52 & 0.51 & 0.48 \\
\hline $\begin{array}{c}\text { Contact with } \\
\text { therapists }\end{array}$ & 0.53 & 0.55 & 0.45 & 0.51 \\
\hline
\end{tabular}

Note. FL: factor loading.

was slightly more likely to lead to illness $(0.48$, younger girls and 0.53 older girls) than to suicidality ( 0.44 and 0.39 ) and thence to substance use $(0.27$ and $0.04 \mathrm{~ns})$. Further, good parental relationships protected girls against suicidality $(-0.14$ and -0.31$)$ and substance use $(-0.25$ and -0.40 ). A good relationship with the parents was a strong protective factor for younger boys against sub- stance use $(-0.43)$, but had no protective effect for older boys. Finally, substance use was slightly related to illness, except among older boys (Fig. 2).

\section{DISCUSSION}

This study tested an SIP model of RAP factors with illness, suicidality, and substance use as outcome measures. The SIP model allowed us to trace 2 risk trajectories. The 1st path went directly from negative mood to illness. Illness as a risk factor connected to negative mood demands further investigation. This path was the greatest risk for girls. We too often neglect the physiological symptoms of stress and moral conflict connected to the adolescent transition, despite its central role in adolescent malaise. The 2nd path led from negative mood through suicidality to substance use. The negative moodsuicidality-substance-use path was most common for the older boys. Popular theories of substance use as selfmedication might suggest that a young man who is depressed or anxious, considers or attempts suicide, and then turns to substance use to "mellow out." We suggest an alternative hypothesis. Negative mood leads to questioning the meaning of life, whether life in general or one's own life and future in particular. Such thoughts put social rules and expectations in abeyance, thus making room for substance use. Substance use, in turn, is a test of the meaningfulness or meaninglessness of life and of one's mortality. In this way substance use, like unsafe driving and unsafe sex are, to paraphrase Einstein, a way of playing dice with the universe, thumbing one's nose at convention without fear of the consequences.

We predicted that secure self and good parental relations would be protective against suicidal thinking and substance use. While good family relationships provided

Table IV. Correlations Between the Variables in the Model

\begin{tabular}{|c|c|c|c|c|c|c|c|}
\hline & Mood & Secure self & Relationships & Suicidal tendencies & Substance use & Illness & Age \\
\hline Secure self & $\begin{array}{c}-0.35 \\
0.000\end{array}$ & & & & & & \\
\hline Relationships & $\begin{array}{r}-0.27 \\
0.000\end{array}$ & $\begin{array}{l}0.36 \\
0.000\end{array}$ & & & & & \\
\hline Suicidal tendencies & $\begin{array}{l}0.40 \\
0.000\end{array}$ & $\begin{array}{c}-0.23 \\
0.000\end{array}$ & $\begin{array}{c}-0.27 \\
0.000\end{array}$ & & & & \\
\hline Substance use & $\begin{array}{l}0.24 \\
0.000\end{array}$ & $\begin{array}{c}-0.14 \\
0.000\end{array}$ & $\begin{array}{c}-0.29 \\
0.000\end{array}$ & $\begin{array}{l}0.24 \\
0.000\end{array}$ & & & \\
\hline Illness & $\begin{array}{l}0.47 \\
0.000\end{array}$ & $\begin{array}{c}-0.25 \\
0.000\end{array}$ & $\begin{array}{c}-0.21 \\
0.000\end{array}$ & $\begin{array}{l}0.35 \\
0.000\end{array}$ & $\begin{array}{l}0.27 \\
0.000\end{array}$ & & \\
\hline Age & $\begin{array}{l}0.07 \\
0.019\end{array}$ & $\begin{array}{c}-0.02 \\
0.497\end{array}$ & $\begin{array}{c}-0.12 \\
0.000\end{array}$ & $\begin{array}{l}0.11 \\
0.000\end{array}$ & $\begin{array}{l}0.32 \\
0.000\end{array}$ & $\begin{array}{l}0.19 \\
0.000\end{array}$ & \\
\hline Gender & $\begin{array}{l}0.30 \\
0.000\end{array}$ & $\begin{array}{c}-0.20 \\
0.000\end{array}$ & $\begin{array}{c}-0.18 \\
0.000\end{array}$ & $\begin{array}{l}0.31 \\
0.000\end{array}$ & $\begin{array}{l}0.01 \\
0.733\end{array}$ & $\begin{array}{l}0.32 \\
0.000\end{array}$ & $\begin{array}{l}0.05 \\
0.109\end{array}$ \\
\hline
\end{tabular}




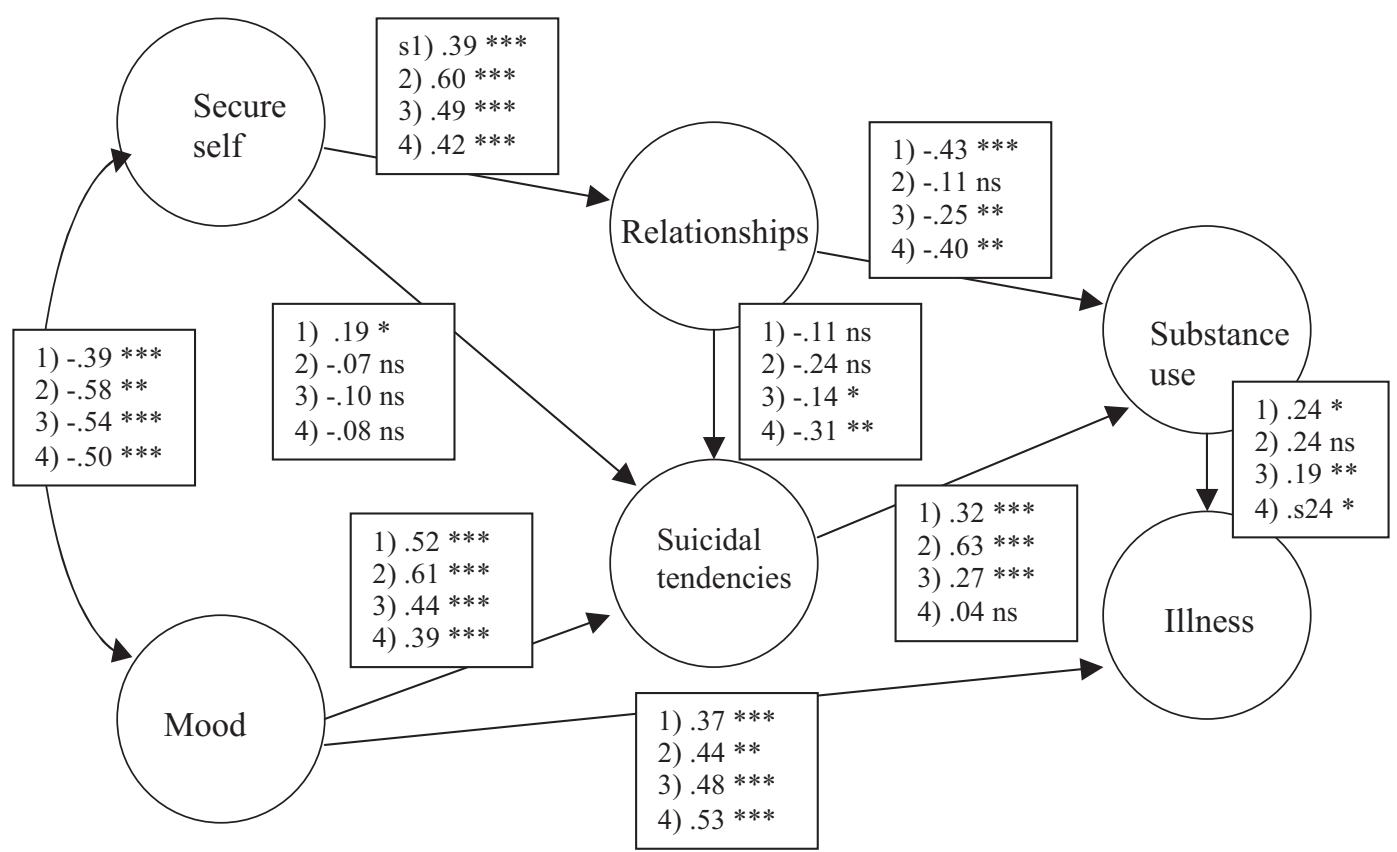

Fig. 2. Model of protective and risk factors on substance use and illness for male and female adolescents. Note. (1) male: 11-15 years; (2) male: 16-20 years; (3) female: $11-15$ years; (4) female: $16-20$ years; ${ }^{*} p<0.05,{ }^{* *} p<0.01,{ }^{* * *} p<0.001$, ns: nonsignificant.

Table V. Fit Indices

\begin{tabular}{lcccccc}
\hline Gender & Age & Chi square & $d f$ & Chi-sqaure/df & NFI & RMSEA \\
\hline Boys & $11-15$ & 103.57 & 65 & 1.59 & 0.99 & 0.04 \\
& $16-20$ & 171.26 & 65 & 2.63 & 0.98 & 0.06 \\
Girls & $11-15$ & 105.18 & 65 & 1.61 & 0.97 & 0.07 \\
& $16-20$ & 128.64 & 65 & 1.97 & 0.97 & 0.07 \\
\hline
\end{tabular}

Note. All chi-square values are significant $(p<0.05)$; NFI: Normed Fit Index; RMSEA: Root Mean Square of Approximation.

some protection against substance use, they were less protective against suicidality. Further, while a secure sense of self is negatively related to mood and - through its relationship to family cohesion - protective against substance use, a secure sense of self offered almost no protection against suicidality.

\section{Implications for Prevention}

These observations are extremely important for prevention programs for two reasons. 1st, many primary and secondary prevention programs make the assumption that helping to develop a positive sense of self esteem, self confidence and competence will be protective (Kahne, 1996; McGee and Williams, 2000). Our results suggest that in the presence of good family relations a secure sense of self is protective against substance use. This means that helping youth to develop a secure sense of self may militate against negative mood, which, in this model, was the core risk. This suggests that prevention efforts might more fruitfully target the negative mood that underlies all 3 risks (illness, suicidality, substance use). 2nd, the relationship between negative mood and illness should not be underestimated or ignored. Illness may be the way that many adolescents experience or metabolize depression and anxiety. What is the long-term outlook for adolescents who are both anxious/depressed and ill? Is the association between illness and mood in this population a reflection of state or trait? While the gender difference in the mood-illness path might be explained by adolescent menstrual malaise, both boys and girls who had negative mood were likely to have frequent symptoms (headache, stomach ache) and injuries.

\section{REFERENCES}

Agid, O., Shapira, B., Zislin, J., Ritsner, M., Hanin, B., Murad, H., Troudart, T., Bloch, M., Heresco-Levy, U., and Lerer, B. (1999). Environment and vulnerability to major psychiatric illness: a case control study of early parental loss in major depression, bipolar disorder and schizophrenia. Mol. Psychiatr. 4: 163172. 
Arbuckle, J. L., and Wothke, W. (1999). Amps 4.0 User's Guide. SPSS, Chicago.

Arènes, J., Janvrin, M.-P., and Baudier, F. (1998). Baromètre Santé jeunes 97/98. Editions CFES, Paris.

Armsden, G. C., and Greenberg, M. T. (1987). The Inventory of Parent and Peer Attachment: Individual differences and their relationship to psychological well-being in adolescence. J. Youth Adolesc. 16: 427-454.

Aro, H. M. (1989). Stress, deveopment and psychosomatic symptoms in adolescence: A comparison of the sexes. Psychiatr. Fennica 20: 101-109.

Aro, H. M., and Palosaari, U. K. (1992). Parental divorce, adolescence, and transition to young adulthood: A follow-up study. Am. J. Orthopsychiatr. 62: 421-429.

Beautrais, A. L. (2000). Risk factors for suicide and attempted suicide among young people. Aust. New Zealand J. Psychiatr. 34: 420-436.

Berardi, D., Leggieri, G., Ceroni, G. B., Rucci, P., Pezzoli, A., Paltineiri, E., Grazian, N., and Ferrari, G. (2002). Depression in primary care: A nationwide epidemiological survey. Fam. Pract. 19: 397-400.

Block, J., and Robins, R. W. (1993). A longitudinal study of consistency and change in self-esteem from early adolescence to early adulthood. Child Dev. 64: 909-923.

Block, J., Gjerde, P. F., and Block, J. H. (1991). Personality antecedents of depressive tendencies in 18-years-olds: A prospective study. $J$. Pers. Soc. Psychol. 60: 726-738.

Boice, M. M. (1998). Chronic illness in adolescence. Adolescence 33: 927-939.

Brink, S. G., and Vanderpool, N. A. (1982). Utilization of child health services by children in single-parent and two-parent families. Child Health Care 11: 22-24.

Brook, J. S., Cohen, P., and Brook, D. W. (1998). Longitudinal study of co-occurring psychiatric disorders and substance use. J. Am. Acad. Child Adolesc. Psychiatr. 37: 322-330.

Brown, R. A., Lewinsohn, P. M., Seeley, J. R., and Wagner, E. F. (1996). Cigarette smoking, major depression, and other psychiatric disorders among adolescents. J. Am. Acad. Child Adolesc. Psychiatr. 35: $1602-1610$

Burke, J. D., Burke, K. C., and Rae, D. S. (1994). Increased rates of drug abuse and dependence after onset of mood or anxiety disorders in adolescence. Hosp. Community Psychiatr. 45: 451-455.

Byrne, B. (2000) Relationships between anxiety, fear, self-esteem, and coping strategies in Adolescence. Adolescence 16: 57-74.

Christie, K. A., Burke, J. D., Jr., Regier, D. A., Rae, D. S., Boyd, J. H., and Locke, B. Z. (1988). Epidemiologic evidence for early onset of mental disorders and higher risk of drug abuse in young adults. Am. J. Psychiatr. 145: 971-975.

Comeau, N., Stewart, S. H., and Loba, P. (2001). The relations of trait anxiety, anxiety sensitivity and sensation seeking to adolescents' motivations for alcohol, cigarette and marijuana use. Addict. Behav. 26: 803-825.

Csorba, J., Rózsa, S., Gádoros, J., Vetró, A., Kaczvinsky, E., Sarungi, E., Makra, J., and Kapornay, K. (2003). Suicidal, depressed vs. nonsuicidal depressed adolescents: Differences in recent psychopathology. J. Affect. Disord. 74: 229-236.

De Goede, M., and Spruijt, E. (1996). Effects of parental divorce and youth unemployment on adolescent health. Patient Educ. Counsel. 29: 269-276.

Deykin, E. Y., Levy, J. C., and Wells, V. W. (1987). Adolescent depression, alcohol and drug abuse. Am. J. Public Health 77: 178-182.

Egger, H. L., Costello, E. J., Erkanli, A., and Angold, A. (1999). Somatic complaints and psychopathology in childen and adolescents: Stomach aches, musculoskeletal pains, and headaches. J. Am. Acad. Child Adolesc. Psychiatr. 38: 852-860.

Fergusson, D., Linskey, M., and Horwood, J. (1996). Comorbidity between depressive disorders and nicotine dependence in a cohort of 16-year-olds. Arch. Gen. Psychiatr. 53: 1043-1047.

Ferron, C., Cordonier, D., Delbos-Piot, I., Schallbetter, P., and Michaud, P. A. (1997). La santé des jeunes en rupture d'aprentissage: une recherché-action sur les modalités de soutien, les determinants de la santé et les facteurs favorisent une reinsertion socio-professionelle. IUMSP, Lausanne.

Fleming, D. M., and Charlton, J. R. (1998). Morbidity and healthcare utilisation of children in households with one adult: Comparative observational study. BMJ 316: 1572-1576.

Franke, G. (1995). Die Symptom-Checkliste von Derogatis (deutsche Version): Skala Ängstlichkeit. Beltz, Göttingen.

Giaconia, R. M., Reinherz, H. Z., Paradis, A. D., Hauf, A. M., and Stashwick, C. K. (2001). Major depression and drug disorders in adolescence: General and specific impairments in early adulthood. J. Am. Acad. Child Adolesc. Psychiatr. 40: 1426-1433.

Guillon, M. S., Crocq, M.-A., and Bailey, P. E. (2003). The relationship between self-esteem and psychiatric disorders in adolescents. Eur. Psychiatr. 18: 59-62.

Harter, S. (1982). The Perceived Competence Scale of Children. Child Dev. 53: 87-97.

Harter, S., and Marold, D. B. (1994). The directonality of the link between self-esteem and affect: Beyond causal modeling. In Cicchetti, D., and Toth, S. L (eds.), Rochester Symposium on Developmental Psychopathology, Vol 5: Disorders and dysfunctions of the self. University of Rochester Press, Rochester, NY, pp. 333-369.

Hautzinger, M., and Bailer, M. (1993). ADS: Allgemeine Depressionsskala. Beltz, Weinheim.

Hawkins, J. D., Catalano, R. F., and Miller, J. Y. (1992). Risk and protective factors for alcohol and other drug problems in adolescence and early adulthood: Implications for substance abuse prevention. Psychol. Bull. 112: 64-105.

Henry, B., Feehan, M., McGee, R., Stanton, W., Moffitt, T. E., and Silva, P. (1993). The importance of conduct problems and depressive symptoms in predicting adolescent substance use. J. Abnorm. Child Psychiatr. 21: 469-480.

Hotopf, M., Carr, S., Mayou, R., Wadsworth, M., and Wessely, S. (1998). Why do children have chronic abdominal pain, and what happens to them when they grow up? Population based cohort study. BMJ 316: 196-200.

Jerusalem, M., and Schwarzer, R. (1992). Self-efficacy as a resource factor in stress appraisal processes. In Schwarzer, R. (ed.), SelfEfficacy: Thought Control of Action. Hemisphere, Washington, DC, pp. 195-213.

Kahne, J. (1996). The politics of self esteem. Am. Educ. Res. J. 33: 3-22.

Laux, L., Glanzmann, P., Schaffner, P., and Spielberger, C. D. (1981). Das State-Trait-Angstinventar (STAI). Beltz, Weinheim.

Levitt, M. Z., and Selman, R. L. (1996). The personal meaning of risk behavior: A developmental perspective on friendship and fighting in early adolesence. In Noam, G., and Fischer, K. (eds.), Development and Vulnerability in Close Relationships. Erlbaum, Mahwah, NJ.

MacLeod, J. S., and Austin, J. K. (2003). Stigma in the lives of adolescents with epilepsy: A review of the literature. Epilepsy Behav. 4: $112-117$

MacLeod, J., Oakes, R., Copello, A., Crome, I., Egger, M., Hickman, M., Oppenkowski, Th., Stokes-Lampard, H., and Smith, G. D. (2004). Psychological and social sequelae of cannabis and other illicit drug use by young people: A systematic review of longitudinal, general population studies. Lancet 363: 1579-1588.

Mauldon, J. (1990). The effect of marital disruption on children's health. Demography 27: 431-446.

McArdie, P., Wiegersma, A., Gilvarry, E., Kolte, B., McCarthy, S., Fitzgerald, M., Brinkley, A., Blom, H., Stoeckel, I., Pierolini, A., Michels, I., Johnson, R., and Quensel, S. (2002). European adolescent substance use: The roles of family structure and gender. Addiction 97: 329-336.

McGee, R., and Williams, S. (2000). Does low self esteem predict health compromising behaviours among adolescents? J. Adolesc. 23: 569582.

Metha, A., Chen, E., Mulvenon, S., and Dode, I. (1998). A theoretical model of adolescent suicide risk. Arch. Suicidial Res. 4: 115133.

Michel, G., Carton, S., Perez-Diaz, F., Mouren-Siméoni, M. C., and Jouvent, R. (1998). Symptomatologie dépressive et consommation 
de substances psycho-actives chez des lycéens. Neuropsychiatr. Infants Rev. 46: 531-536.

Montgomery, L. E., Kiely, J. L, and Pappas, G. (1996). The effects of poverty, race, and family structure on US children's health: Data from the NHIS, 1978 through 1980 and 1989 through 1991. Am.J. Public Health 86: 1401-1405.

Moyes, C. D. (1980). Epidemiology of serious head injuries in childhood. Child Care Health Dev. 6: 1-9.

Narring, F., Miauton, L., and Michaud, P.-A. (2003). Chronic condition and life style in adolescence: Results of a cross sectional survey on the health of 15-20 year olds in Switzerland. J. Adolesc. Health 32: 163 (poster abstract).

Narring, F., Tschumper, A., Michaud, P.-A., Vanetta, F., Meyer, R., Wydler, H., Vuille, J., Paccaud, F., and Gutzwiler, F. (1994). La santé des adolescents en Suisse: Rapport d'une enquÍte nationale sur la santé et les styles de vie des 15-20 ans. IUMSP, Lausanne.

National Institute of Mental Health (2002). Brief notes on the mental health of children and adolescents. Retrieved October 3, 2002, from National Institute of Mental Health Web site: http://www.nimh.nih.gov/publicat/childnotes.cfm.

National Institute of Mental Health (2003). Depression in children and adolescents: A fact sheet for physicians. Retrieved October 28, 2000, from National Institute of Mental Health Web site: http://www.nimh.nih.gov/publicat/depchildresfact.cfm.

Norton, G. R. (2001). Substance use/abuse and anxiety sensitivity: What are the relationships? Addict. Behav. 26: 935-946.

Ormel, J., Vonkroff, M., Oldehinkel, A. J., Simon, G., Tiemens, B. G., and Ustün, T. B. (1999). Onset of disability in depressed and no-depressed primary care patients. Psychol. Med. 29: 847853.

Roberts, I. (1994). Sole parenthood and the risk of child pedestrian injury. J. Paediatr. Child Health 30: 530-532.
Rosenberg, M., Schooler, C., and Schoenbach, C. (1989). Self-esteem and adolescent problems: Modeling reciprocal effects. Am. Sociol. Rev. 54: 1004-1018.

Rosenberg, M., Schooler, C., Schoenbach, C., and Rosenberg, F. (1995). Global self-esteem and specific self-esteem: Different concepts, different outcomes. Am. Sociol. Rev. 60: 141-156.

Shrier, L. A., Harris, S. K., Sternberg, M., and Beardslee, W. R. (2001) Associations of depression, self-esteem and substance use with sexual risk among adolescents. Prev. Med. 33: 179-189.

Statham, A., and Roades, K. (2001). Gender and self-esteem. In Owens, T., Stryker, S., and Goodman, N. (eds.), Extending Self-Esteem Theory and Research. Cambridge University Press, Cambridge, UK.

Wadsworth, J., Burnell, I., Taylor, B., and Butler, N. (1983). Family type and accidents in preschool children. J. Epidemiol. Community Health Epidemiol 37: 100-104.

Wilens, T. E., Biederman, J., Abrantes, A. M., and Spencer, T. J. (1997). Clinical characteristics of psychiatrically referred adolescent outpatients with substance use disorder. J. Am. Acad. Child Adolesc. Psychiatr. 36: 941-947.

Wingert, W. A., Larson, W., and Friedman, D. B. (1968). The influence of family organization on the utilization of pediatric emergency services. Pediatrics 42: 743-751.

Williams, P. G., Colder, C. R., Richards, M. H., and Scalzo, C. A. (2002). The role of self-assessed health in the relationship between gender and depressive symptoms among adolescents. J. Pediatr. Psychol. 27: 509-517.

Wills, T. A., Sandy, J. M., Yaeger, A., and Shinar, O. (2001). Family risk factors and adolescent substance use: Moderation effects for temperament dimensions. J. Dev. Behav. Pediatr. 37: 283-297.

Zweig, J. M., Phillips, S. D., and Duberstein Lindberg, L. (2002). Predicting adolescent profiles of risk: looking beyond demographics. J. Adolesc. Health 31: 343-353. 